УДК 372. 881. 111.1

\title{
СОЦИО-ЛИНГВИСТИЧЕСКИЙ АСПЕКТ В ФОРМИРОВАНИИ МЕЖКУЛЬТУРНОЙ КОММУНИКАЦИИ: ИНКУЛЬТУРАЦИЯ, АККУЛЬТУРАЦИЯ И АССИМИЛЯЦИЯ
}

\author{
Нурутдинова А.Р., Панфилова Е.В.
}

В наши дни присутствует больше возможностей для обмена знаниями, исследовательскими проектами и расширения международного сотрудничества, что в свою очередь обуславливает необходимость развития сочио-лингвистической коммуникативной компетенции. Потенцииал межкультурных и международных контактов увеличивается, и подразумевает постоянное и непрерывное взаимодействие и поиск новых вербальных и невербальных систем общения. Независимо от уровня осведомленности, различные социально-психологические и сочиокультурные процессы действуют в рамках каждого межкультурного взаимодействия, где знание иностранного языка не является достаточным, необходимым являются знания «культурных корней». Успешная межкультурная коммуникация предполагает еще и умение адекватно интерпретировать коммуникативное поведение представителя иностранного социума, а также готовность участников общения к восприятию другой формы коммуникативного поведения, пониманию его различий от культуры к культуре. Именно, незнание чужой культуры, незнание различий и сходств культур, особенно, когда речь идет о взаимодействии с ними является основной причиной большинства культурньхх конфликтов.

Цель - классификация основ и проблем межкультурного общения; а также анализ стратегий сближения инокультурных знаний, направленных на предотвращение не только смысловых, но и культурных сбоев в коммуникации: а именно, вербальное и невербальное обеспечение межкультурной коммуникации. 
Метод или методология проведения работы. Основу исследования образуют метод интроспекиии, метод наблюдения в естественных условиях, методика референциальной коммуникации.

Результаты. Рассматриваемый результат социализации -инкультурация и аккультураци - в поликультурной среде естественны: ассимиляция возможна в результате компромисса с доминирующим обществом. Осознание своей идентичности - это сообщение к самопознанию навыков и способностей, вызывающее формирование самоутверждения при поддержке, когда человек начинает реализовывать себя не только в обществе, где он родился, но и в любой среде обитания иностранной культуры. Именно, многоязычная образовательная поликультурная среда способствует естественному ходу сочиализации, инкультурации и аккультурации человека, тем самым исключает возможную ассимиляциию.

Область применения результатов. Результаты исследования могут быть применены в сфере педагогического проектирования бесконфликтного поведения и психолингвистики.

Ключевые слова: сочиализация; инокультура; психолингвистика; поликультурность; многоязычие; ассимиляциия.

\section{SOCIO-LINGUISTIC ASPECT IN THE FORMATION OF INTERCULTURAL COMMUNICATION: INCULTURATION, ACCULTURATION AND ASSIMILATION}

\section{Nurutdinova A.R., Panfilova E.V.}

Today there are more opportunities for the knowledge exchange, research projects and the international cooperation expansion, which in turn are necessary for the socio-linguistic communicative competence development. The potential of intercultural and international contacts is increasing, and implies constant and continuous interaction and the search for new verbal and non-verbal communication systems. Regardless of the awareness level, various socio-psychological and sociocultural processes 
operate within each intercultural interaction, where knowledge of a foreign language is not sufficient, knowledge of "cultural roots" is necessary. Successful intercultural communication also presupposes the ability to adequately interpret the communicative behavior of a representative of a foreign society, as well as the participants'willingness in communication to perceive another of communicative behavior form, to understand its differences from culture to culture. Namely, ignorance of a foreign culture, ignorance of differences and similarities of cultures, especially when it comes to interacting with them, is the main cause of most cultural conflicts.

Purpose is the foundations' classification and of intercultural communication problems; as well as the strategies for convergence of foreign cultural knowledge aimed at preventing not only semantic, but also cultural failures in communication: namely, verbal and non-verbal support for intercultural communication.

Methodology. The basis of the research is formed by the method of introspection, the method of observation in vivo, the technique of referential communication.

Results. The considered result of socialization - inculturation and acculturation - is natural in a multicultural environment: assimilation is possible as a result of a compromise with a dominant society. Awareness of their identity is a message to self-knowledge of skills and abilities, causing the formation of self-assertion with support, when a person begins to realize himself not only in the society where he was born, but in any environment of a foreign culture. Namely, a multilingual educational multicultural environment contributes to the natural course of socialization, inculturation and acculturation of a person, thereby eliminating possible assimilation.

Practical implications. The research results can be applied in the field of pedagogical design of conflict-free behavior and psycholinguistics.

Keywords: socialization; foreign culture; psycholinguistics; multiculturalism; multilingualism; assimilation.

Язык, представленный набором конвенциональных символов, выполняет функции коммуникации и познания, и является средством 
хранения \передачи информации, которое касается управления человеческим поведением, выражения самосознания личности. Как составная часть культуры и ее орудие, язык это действительность культуры и выражает специфические черты национальной ментальности; это главный «выразитель» самобытности культуры как посредник в межкультурном коммуникационном процессе.

Роль идентичности в изучении языка и межкультурном общении были основаны на социально-психологических теориях межгрупповой динамики и на теоретизировании социальных наук. Социокультурная перспектива в изучении языка, идентичности и межкультурного общения - как инструмент для достижения социальных и психологических целей и как ресурс для управления повседневной деятельностью.

Влияние и сила языка являются значимыми для представителей культурных групп (этнической, расовой, культурной или гендерной). Каждое речевое сообщество имеет свои нормы, формы и коды для взаимодействия группы людей различаются во многих отношениях: по частоте и значению речи, интерпретации выступлений и общих языковых форм. Речевое сообщество поддерживает нормы и правила общения, но может постепенно их менять. С другой стороны, в каждом речевом сообществе есть степень индивидуального отклонения от норм. Не все участники группы общаются одинаково. Члены группы делятся речевым кодом, системой символов, знаков, значений и правил в конкретной ситуации и взаимодействии. Несколько аспектов, таких как отношения, возраст, пол, социальный статус и поколение, влияют на общение. Аналогично, соотношение вербального и невербального общения варьируется в разных речевых сообществах.

Правила разговора определяют, что уместно и неуместно в ситуации с конкретными партнерами по общению. Мы автоматически осознаем, что говорить, а что не говорить и каким образом. Правила взаимодействия помогают человеку узнать, как вести себя с другими в конкретной ситуации. Язык используется не только как средство общения, но также как маркер или индикатор культурной 
идентичности говорящего. Идентичность сообщается посредством определенного использования языка во время взаимодействия. Определенные типы выражений используются для выражения принадлежности к группе, но также иногда они используются для исключения, разделения или различий.

Овладение иноязычным кодом, позволяющим успешно осуществлять межкультурное взаимодействие, предполагает изучение особенностей культуры, определяющих специфику общественного и делового поведения партнера, детерминируемого влиянием исторических традиций и обычаев, образа жизни и т.П. Поэтому иностранные языки как средство коммуникации между представителями разных народов и культур должны изучаться в неразрывном единстве с миром и культурой народов, говорящих на этих языках (раньше у нас иностранный язык изучался в отрыве от его социокультурного контекста как самоцель и практически не нес функциональной нагрузки).

Реальное употребление слов, реальное речевоспроизводство в значительной степени определяется знанием социальной и культурной жизни говорящего на этом языке речевого коллектива. Язык не существует вне культуры, т.е. вне социально унаследованной совокупности практических навыков и идей, характеризующих наш образ жизни. Поскольку в основе языковых структур лежат социокультурные структуры, то для активного использования языка как средства общения необходимо как можно глубже знать «мир изучаемого языка».

Языковая картина мира есть отражение социокультурной картины мира. Не зная мир изучаемого языка, невозможно освоить язык как средство общения, он может быть освоен лишь как способ хранения и передачи информации, лишенный культуры носителя. Этим, кстати, объясняются и неудачи с искусственными языками, так и не получившими широкого распространения и обреченными на умирание. Именно поэтому изучение иностранного языка предполагает не только усвоение плана выражения некоторого языкового явления, но и плана его содержания, т.е. выработки в сознании обучающихся 
понятия о новых предметах и явлениях, не имеющих аналогов ни в их родной культуре, ни в их родном языке. Для этого в преподавание языка необходимо включать элементы страноведения.

Комплексный подход, сочетающий лингвистическую подготовку и знания социокультурного контекста изучаемого языка, позволяет обеспечить адекватный перевод с неродного языка на родной.

Механизмы овладения иностранным языком изучаются психологами, этнологами, лингвистами. Принципы усвоения второго языка, наблюдаемые в бикультурной и билингвистичной среде, несколько иные, чем в однородной культурной и моноязычной среде. Здесь наблюдается явление интерференции (перенесения, привнесения) элементов культуры $A$ в культуру $B$ и наоборот.

Ребенок, социализированный в бикультурной (мультикультурной) среде, имеет установку на наличие в культурном пространстве альтернативной символической системы, которая не воспринимается чуждой, угрожающей разрушением собственной культурной системы, наоборот, способствующей овладению другой культурой. Таким образом, формируется установка на культурную толерантность. С повышением материального благосостояния общества и его культурного уровня такие состояния культурного и языкового дву- и многоязычия имеют тенденцию к количественному росту и качественной стабильности.

Культуры, которые длительное время находились под инокультурным влиянием, а также маргинальные культуры обнаруживают феномен билингвизма. Языки могут претерпевать синтетическое смешение (если принадлежат к родственной ветви) или сосуществовать сегрегационно (в быту употребляется один язык, в социальном общении - другой). Процесс овладения иностранным языком основывается на тех же навыках, которые получены при овладении родным языком. Не удивительно, что человек, овладевший одним иностранным языком, с большей легкостью овладевает вторым, третьим, т.е. становится полиглотом. Однако описанный процесс интерференции нельзя оценивать однозначно. Если на лингвистическом уровне интерференция зачастую помогает межкультурной 
коммуникации, то на психологическом она зачастую мешает адекватному пониманию.

Английский язык, как международный язык, широко используется сегодня во всем мире. Существенным фактором такого широкого использования английского языка является тот факт, что большинство пользователей английского языка сегодня не являются носителями языка.

Английский язык «путешествовал» по многим частям мира и использовался для различных целей. Это явление создало позитивное взаимодействие, а также вызвало напряженность между глобальными и местными силами и имело серьезные лингвистические, идеологические, социокультурные, политические и педагогические последствия. Поскольку английский язык способствует более сложным отношениям внутри и между сообществами говорящих по всему миру, его роль в качестве глобального языка подлежит обсуждению.

Спрос на английский язык быстро возрос среди взрослых учащихся, включая иммигрантов в англоязычные страны, бизнесменов, вовлеченных в мировую экономику, и тех, кто просто хочет путешествовать в качестве туристов. Во многих странах в результате глобализации рабочей силы, предполагаемой необходимости повышения экономической конкурентоспособности и перехода к обучению на протяжении всей жизни в обществе и на рабочем месте были созданы крупномасштабные программы обучения английскому языку для взрослых учащихся.

Английский, как международный язык, также связан с исследованиями в области межкультурного общения. Сегодня английский язык широко используется для межкультурного общения на глобальном уровне. Становится все более общепризнанным, что межкультурная компетенция должна рассматриваться как основной элемент владения английским языком, когда она используется для международного общения.

Несмотря на потребность в некоторой культуре, пользователи английского как международного языка не должны усваивать культурные нормы стран, где говорят на родном языке, чтобы эффектив- 
но использовать язык. Поскольку английский как международный язык не обязательно принадлежит какой-либо стране, но учителям необходимо признать, что необходимо расширять кругозор своих студентов за пределы чисто лингвистических аспектов, уделяя внимание культурному фону языка и пытаться поднять некоторую межкультурную осведомленность, которая со временем приведет к межкультурной коммуникативной компетенции.

О межкультурной осведомленности в изучении языка часто говорят как о способности осознавать культурную относительность после чтения, письма, аудирования и разговорной речи. Сам язык определяется культурой. Мы не можем быть компетентными в языке, если мы также не понимаем культуру, которая сформировала и проинформировала его. Мы не можем выучить второй язык, если у нас нет понимания этой культуры и того, как эта культура связана с нашим собственным первым языком, первой культурой. Поэтому важно иметь не только культурную осведомленность, но и межкультурную осведомленность.

Изучение коммуникативного поведения представителей иноязычного социума, их лингвосоциологических и культурологических особенностей способствует приобщению «неносителей» языка к концептуальной системе, картине мировидения, ценностным ориентирам его носителей, сокращению межкультурной дистанции, воспитанию готовности адаптироваться к культуре другого народа, иному социокультурному контексту взаимодействия и воздействия с целью выработки оптимальной стратегии сотрудничества и общения на иностранном языке.

Безусловно, в межкультурной коммуникации есть области значений, общих для всего человечества, и значений, одинаковых для носителей разных языков. Так, в деловом общении понимание облегчается за счет знакомого всем участникам общения и одинакового для всех них предметного содержания деятельности. Тем не менее, содержательные и смысловые барьеры, возникающие в межкультурной коммуникации, - скорее правило, чем исключение, поскольку каждый участник коммуникации привносит в нее собственную си- 
стему смыслов, присущих ему как индивидуальности и как представителю соответствующей культуры. Именно последние выходят на первый план в межкультурной коммуникации.

Дети, лишенные человеческого общения в раннем возрасте, не получают должного развития, плохо социализируются без дополнительных вмешательств. Развитие психики и интеллекта ребенка напрямую связано с его социализацией и отражается в конкретных проявлениях воздействия общества на ребенка. Семья, ближайшая социальная среда (соседи, родственники, друзья), система образования, средства массовой информации, государство оказывают социализирующее влияние на человека. Социализация не тождественна воспитанию. Воспитание - это целенаправленная система психолого-педагогических воздействий на ребенка со стороны родителей и педагогов с целью формирования у него определенных качеств и поведения в соответствии с некой идеальной, социальной моделью. В общении ребенок играет активную роль (что-то выбирает, что-то отвергает).

Необходимо отметить, что смысловое наполнение понятий «социализация» и «инкультурация» является дискуссионным. Под социализацией чаще всего понимается успешная интеграция человека в человеческое общество, приобретение опыта, необходимого для выполнения социальных ролей. Социализация - это основной процесс включения человека в общество, элементами которого могут быть воспитание, обучение, адаптация и взросление, а типы социализации, применяемые к культуре, - это инкультурация, аккультурация и ассимиляция.

Мы согласны с позицией исследователей, полагающих, что инкультурация представляет собой сложный и многофазный процесс проникновения индивида в культуру, овладения им привычками, нормами и поведением, принятыми в данной культуре. Термин «инкультурация» был разработан американскими учеными, занимающимися культурной антропологией. Впервые данное понятие ввел американский этнограф-антрополог Мелвилл Джин Херсковиц (1895-1963) в работе «Культурная антропология» (1948). М. Херсковиц предложил «концепцию «инкультурации» как процесса усвоения 
человеком присущей ему культуры мировоззрения и поведения», в результате которого формируются его когнитивные, эмоциональные и поведенческие сходства с представителями этой культуры и отличие от представителей других культур. Инкультурация начинается с момента рождения - с приобретения первых навыков ребенка и овладения речью - и происходит без специальной подготовки, в ходе повседневного взаимодействия со взрослыми на основе накопления собственного опыта.

Американский ученый, К.К.М. Клакхон (1905-1960) ввел аналогично значимый термин «культура» вместо термина «социализация», существовавшего в рамках английской социальной антропологии, который не охватывал «процессов усвоения когнитивных аспектов культуры: знания, верования, ценности». В отличие от английских исследователей, американские антропологи сосредоточились на изучении культуры и общества, поэтому термин «инкультурация» был для них более органичным.

Изучение научно-педагогической литературы позволило обозначить, что процесс инкультурации предполагает двустороннее взаимодействие человека и культуры: с одной стороны, культура определяет основные черты личности человека, а с другой стороны, сам человек влияет на свою культуру, формируя и трансформируя ее. Инкультурация - это процесс приобретения культурных навыков, проникновения в культуру.

Понятие инкультурации обычно используется в узком и широком смысле: в узком смысле это означает усвоение ребенком культурных норм и ценностей, в более широком контексте - процесс, который не ограничивается периодом раннего детства. и включает в себя процессы усвоения культурных паттернов взрослого человека. Данный термин применим к иммигрантам, адаптирующимся к новым культурным условиям, а также используется в контексте исследования культурных контактов и культурных изменений.

Результатом процесса инкультурации является усвоение членом определенного общества основных черт и содержания культуры этого общества, а также менталитета, культурных моделей и стереоти- 
пов в поведении и мышлении. Человек изучает традиции и нормы поведения, принятые в его родной культуре.

Теоретико-методологический анализ существующих научных подходов и рефлексия педагогических практик показывают, что на коллективном уровне инкультурация формирует следующие важные навыки: виды общения с другими людьми; формы контроля над своим поведением и эмоциями; способы удовлетворения основных потребностей; предполагаемое отношение к различным явлениям окружающего нас мира; эмоциональное и поведенческое сходство человека с другими представителями данной культуры и отличие от представителей других культур.

На индивидуальном уровне процесс инкультурации выражается в ежедневном общении человека с другими членами общества, родственниками, друзьями или незнакомцами, связанными с той же культурой.

Абсолютно логично, что важной практической ценностью процесса инкультурации можно назвать то, что человек учится реагировать на определенные события, признаки внимания, сигналы в различных жизненных ситуациях, т. е. получает необходимые знания, навыки и умения для того, чтобы успешно существовать в обществе.

Выдающийся немецкий ученый и педагог Адольф Дистервег подчеркнул, что «принцип природного соответствия представляет собой вечную цель человеческих устремлений на протяжении всей деятельности, он должен постоянно приближаться к нему. Содержание деятельности человека наполнено культурной средой страны, региона, конкретного общества, пространства и т. е., того места, где он родился.

Доктрина Дистверга наводит нас на размышление о том, что принцип природного соответствия и принцип культурного соответствия связаны друг с другом, поэтому невозможно сопоставить их, как это было сделано его научными коллегами. Однако не следует забывать тот факт, что среди представителей культурной антропологии существовало длительное отчаянное сопротивление доминированию того или иного принципа. 
В. Кумарин, анализируя два принципа А. Дистервега, указывает, что «культурная среда обитания человека является производной от его природы», его способности говорить, думать, работать, слышать голос инстинктов - самосохранение, размножение, свободу (возможность выбора ), безопасность - от врожденной потребности в реализации всех способностей.

Когда образование опирается на общечеловеческие ценности и учитывает особенности мировоззрения и убеждения определенного лингвокультурного сообщества, начинает действовать принцип культурного соответствия. Этот принцип помогает человеку чувствовать себя комфортно в разных отраслях культуры (бытовая, физическая, материальная, духовная, политическая, экономическая, интеллектуальная, моральная). Цели, содержание, методы воспитания рассматриваются как традиции, стиль социализации и инкультурации, сопровождающие аккультурацию и ассимиляцию.

В современных исследованиях процессы социализации и инкультурации предполагают усвоение системы культурных ценностей, правил и стандартов поведения индивидом того общества, к которому он принадлежит. Однако человек, общаясь с представителями других культур, часто не может предсказать их поведение, основываясь только на его собственных культурных нормах и правилах. В то же время исследователи предполагают, что индивид может одновременно стать членом нескольких социальных и культурных сообществ. В научных трудах А.П. Садохина отмечается, что «в культурной антропологии существовала аксиома утверждения», согласно которой каждый человек выступает в роли носителя той культуры, в которой он вырос и был создан как личность. Когда человек находится в своем собственном лингвокультурном сообществе, он не обращает внимания на существенные характерные черты своей культуры. Эти особенности окружают его с самого раннего детства, и человек воспринимает их как реальность. Но когда он общается с представителями другой культуры, эти черты проявляются в его деятельности и иногда бывают совершенно иными, чем в родной культуре. Затем человек начинает понимать, что существуют другие типы поведения и 
способы мышления. Различные представления о мире трансформируются в сознании человека в идеи, установки, стереотипы, ожидания, которые становятся для него важными регуляторами его поведения и общения. Процесс идентификации возникает, когда человек анализирует, сравнивает и противопоставляет взгляды других людей, их позиции и мнения при его реальном контакте с представителями другой культуры. Во время своей работы с другими членами сообщества он формирует личную идентификацию, которая определяется его знаниями и представлениями. Между тем наличие особенностей культуры означает, что основной задачей культурной антропологии является наблюдение, регистрация, описание и интерпретация повседневного поведения людей с целью поиска объяснения причин и возможных последствий.

Исследователи подчеркивают, что «социализация - это двусторонний процесс». С одной стороны, человек приобретает социальный опыт, когда входит в сообщество людей своего общества, начинает социальные коммуникации и становится членом этого общества. С другой стороны, он активно воспроизводит эту систему в своей деятельности. Каждый день человек принимает информацию, которая его окружает, анализирует и обобщает, вовлекая в интеллектуальную деятельность свои внутренние психологические переживания. Общение с людьми, внутренний опыт и приобретение социального взаимодействия помогают человеку сформироваться как личности. Человек начинает входить в общество, социальную среду, начинает приобретать систему социокультурных ценностей общества и чувствует себя комфортно и уверенно как гражданин. По словам С.П. Волохова, различие факторов социализации и инкультурации в едином целостном процессе становления личности отражается социальным соответствием «процесс социализации и культурной индивидуализации - процесс инкультурации». Социализация предполагает интеграцию человека в общество, а «термин «инкультурация» означает понимание и принятие мира и поведения, присущих его культуре. В результате когнитивные, эмоциональные и поведенческие стратегии человека становятся похожими на представителей 
его культуры и отличаются от мировоззрения людей другой культуры. Когда человек рождается, он сразу входит в родную культуру. Этот процесс поведения и речи продолжается в течение всей жизни. В ходе этого процесса происходит формирование фундаментальных навыков общения с людьми, формы контроля поведения, выражения эмоций. В процессе инкультурации человек развивает свою культурную компетентность как существенную часть усвоения языка, традиций, обычаев и человеческих ценностей. Когда человек входит в другую социальную среду, язык и культуру, происходит процесс аккультурации. Человек может иметь разный уровень аккультурации, например, частичный или полный. При полной аккультурации человек погружается в чужую культуру и забывает родные ценности. В результате этого мы можем наблюдать ассимиляцию.

В связи с этим в условиях глобализации, многоязычия и поликультурного пространства, приводящих к инкультурации и аккультурации, высока вероятность потери сохранения уникальности личности и ее безопасности в среде обитания. Так называемая «языковая личность», как правило, находится в опасности. Такой индивид хорошо знает иностранные языки, предвидит и принимает ценность иностранной культуры, живет и развивает свою профессиональную деятельность в многоязычной поликультурной среде. Языковая личность, будучи высокопрофессиональным специалистом в области лингвистики, воспринимает культуру других людей, толерантно, а иногда с восхищением копирует их поведение, незаметно начинает следовать за ними не только внешне (жесты, мимика, одежда и т.п.) но и внутренне. Язык человека неосознанно меняется, с восхищением воспринимая некоторые поведенческие явления других людей. Таким образом, он влюбляется в изучаемый язык и литературу, искусство и даже представителей этой нации. Мы также признаем, что в процессе аккультурации человек осознает свою личность. С другой стороны, языковой человек легко трансформирует себя, сознательно принимая особенности поведения других людей.

Эдмунд Гуссерль считает, что «жизненный мир» - мир повседневности - мир здравого смысла - источник всех теорий и концеп- 
ций науки, является фундаментальной предпосылкой культуры и цивилизации». Этот мир наполнен «значениями» сознания, через которые мы воспринимаем объекты жизни. Все виды реальности, с которыми человек имеет дело, объясняются актами сознания. Объективная реальность без сознания не существует. Человеческие переживания рассматриваются как преломление сквозь призму сознания ценностей человека в реальной жизни. Другими словами, человеческая жизнь - это единый процесс формирования жизни человека: человек одновременно является тем, кто он есть, и кем он стремится быть. Например, индивид, благодаря своей языковой личности незаметно меняется, внешне и внутренне, принимая произвольное или непроизвольное произношение, стиль речи, поведение тех людей, язык которых изучает. В этих условиях, обладая уникальной способностью меняться, человек сталкивается с угрозой ассимиляции с другой культурой. Аккультурация возникает, «когда языковая личность приобретает знания и навыки, необходимые для жизни в чужой среде».

Семьи, проживающие в другой стране, входят в группу языковых лиц. На Международной конференции КФУ студентка 4-го курса сообщила: «... Мать и дочь - китаянки. Они переехали в Штаты, когда Сяо Ю (дочери) было семь лет. Ни мать, ни дочь не знали английского языка, от чего обе очень страдали. Они сказали, что им ужасно тяжело в чужой языковой среде. Они хотели «не быть чужими». Они хотели стать «такими, как окружающие люди». Основные проблемы в таких ситуациях объективные (страх и трудность пребывания в иноязычной среде), и в то же время субъективные, психологически хотят быть похожими на других людей (они хотели не быть чужими, они хотели стать как окружающие люди). Наличие сильного внутреннего желания «стать как окружающие» вызывает не только аккультурацию человека, но и ассимиляцию. Ассимиляция рассматривается нами как форма, когда человек полностью принимает ценности и нормы другой культуры, отказ от собственных норм и ценностей. Отметим, что в современной научной литературе под аккультурацией понимается «процесс взаимного влияния раз- 
личных культур, при котором все или часть представителей одной культуры (получателей) перенимают нормы, ценности и традиции другой (донорской культуры)». В процессе аккультурации человек должен решать две проблемы одновременно - сохранение культурной самобытности и вхождение в чужую культуру.

Процесс аккультурации в билингвальной семье несет в себе ряд проблем. Двуязычная семья - это своеобразное общество, которое как среда обитания человека, производная его природы, оказывает двойное влияние на человека. Практика показывает, что члены такой семьи пытаются следовать принципу природного соответствия, согласно ведущей роли отца или матери. Члены семей билингвов одинаково хорошо говорят на двух языках. Некоторые семьи выбирают один язык и, следовательно, одну культуру, особенно в условиях города и районных центров. Рассмотрим пример двуязычной семьи, в которой мать - русская и носитель русского языка, а отец татарин и носитель татарского языка. Оба родителя прекрасно знают свои родные языки. Язык общения внутри семьи - татарский, вне дома - русский. Родители выбирают русский язык как доминирующий. Татарский язык становится вторым языком и используется только для семейного общения.

Абсолютно логично, что проблема аккультурации языковой личности, членов двуязычных семей и людей, живущих, работающих в других странах, заключается в возможности полной ассимиляции в эту среду обитания. Следовательно, возникает вопрос о способах самосохранения уникальности в условиях многоязычия. Проблема, с нашей точки зрения, надолго займет умы психологов и педагогов, поскольку нет универсальных приемов и способов самосохранения уникальности каждого человека. Результаты анализа теоретических источников позволяют сделать вывод, что «в современных условиях география проблемы расширяется и углубляется из-за мигрантов, которые несут экономические, культурные и даже физические риски для человека и не только».

Билингвальная семья, в которой говорят на двух языках, естественным образом снимает данную проблему принципами природ- 
ного и культурного соответствия образования. В этом случае дети могут стать членами двух социальных и культурных сообществ одновременно (русского и татарского).

Частичное решение проблемы самосохранения личности человека заключается в самопознании и выборе места проживания в современном обществе. Аккультурация происходит в тех случаях, когда: а) человек прекрасно знает свой родной язык, культуру (быт, обычаи, литературу, искусство и другие достижения, историю своего народа); б) он знает свои собственные возможности и способности, обладает знаниями в той сфере, где работает и живет. Процесс инкультурации и аккультурации протекает естественным образом параллельно с социализацией индивида, если он, обладает способностью контролировать себя в любых жизненных ситуациях, и может найти какой-либо выход из «точек бифуркаций», не причиняя вреда себе и другим людям.

В заключение следует отметить, что язык можно понимать как компонент и инструмент культуры. В то же время «язык, культура и личностные качества человека являются своеобразными способами и средствами самосохранения личности и самозащиты от риска ассимиляции в другой среде». Языковая личность подвергается инкультурации и аккультурации, частично овладев традициями и ценностями иностранной культуры, чтобы жить и работать в этой среде. Билингвальная семья - это универсальная и уникальная среда социализации, инкультурации и аккультурации лиц, которые могут быть членами нескольких социальных и культурных сообществ одновременно.

Информация о конфликте интересов. Авторы заявляют об отсутствии конфликта интересов.

\section{Сиисок литературы / References}

1. Charalambous C. (2019). Language education and 'Conflicted heritage': Implications for teaching and learning. Modern Language Journal, 103(4), 874-891. doi:10.1111/modl.12593 
2. Fox R., Corretjer O., \& Webb K. (2019). Benefits of foreign language learning and bilingualism: An analysis of published empirical research 2012-2019. Foreign Language Annals, 52(4), 699-726. doi:10.1111/ flan. 12424.

3. Lorenz E., Bonnie R.J., Feindt K., Rahbari S., \& Siemund P. (2019). Cross-linguistic influence in unbalanced bilingual heritage speakers on subsequent language acquisition: Evidence from pronominal object placement in ditransitive clauses. International Journal of Bilingualism, 23(6), 1410-1430. doi:10.1177/1367006918791296.

4. Lorette P., \& Dewaele J. (2019). The relationship between bi/multilingualism, nativeness, proficiency and multimodal emotion recognition ability. International Journal of Bilingualism, 23(6), 1502-1516. doi:10.1177/1367006918808042.

5. Lundberg A. (2019). Teachers' viewpoints about an educational reform concerning multilingualism in german-speaking switzerland. Learning and Instruction, 64 doi:10.1016/j.learninstruc.2019.101244.

6. Nurutdinova A.R., Dmitrieva E.V., Nelyubina E.A., Nurova L.R., \& Wagner K.R. (2018). The interactive education in teaching languages: Microblogging as the way to improve postgraduate students' communicative interaction in english. XLinguae, 11(2), 120-135. doi:10.18355/ XL.2018.11.02.10.

7. Ramírez-Esparza N., García-Sierra A., \& Jiang S. (2020). The current standing of bilingualism in today's globalized world: A socio-ecological perspective. Current Opinion in Psychology, 32, 124-128. doi:10.1016/j. copsyc.2019.06.038.

8. Verkuyten M., \& Yogeeswaran K. (2020). Cultural diversity and its implications for intergroup relations. Current Opinion in Psychology, 32, 1-5. doi:10.1016/j.copsyc.2019.06.010.

\section{ДАННЫЕ ОБ АВТОРАХ}

Нурутдинова Аида Рустамовна, и.о. зав.каф. контрастивной лингвистики, доцент, кандидат педагогических наук ФГАОУ ВО «Казанский (Приволжский) федеральный универcumem» 
ул. Кремлевская, 18, г. Казань, Татарстан, 420008, Российская Федерачия

AiRNurutdinova@kpfu.ru

\section{Панфилова Евгения Владимировна}

Автономная некоммерческая организачия дополнительного профессионального образования "Международный» Академический Центр Образования»

2. Казань, Татарстан, Российская Федеращия

\section{DATA ABOUT THE AUTHORS}

Nurutdinova Aida Rustamovna, Acting Head of Department contrastive linguistics, Associate Professor, $\mathrm{PhD}$ in pedagogical sciences, Kazan (Volga) Federal University

18, Kremlevskaya Str., Kazan, Tatarstan, 420008, Russian Federation AiRNurutdinova@kpfu.ru

SPIN-code: 5215-4243

ORCID: 0000-0001-5759-0820

ResearcherID: $\mathrm{N}-8480-2015$

Scopus Author ID: 57190573898

\section{Panfilova Evgenia Vladimirovna}

«The International» Academic Centre for Language and Development (IACLD)

Kazan, Tatarstan, Russian Federation 